\title{
The Organizational Climate for Sustainable Commuting: An Italian Validation Study in the Academic Sector
}

\author{
Guido Martinolli ${ }^{1,2, *(D)}$, Marco de Angelis ${ }^{1}\left(\mathbb{D}\right.$, Núria Tordera $^{2}(\mathbb{D})$ and Luca Pietrantoni $^{1}(\mathbb{D}$ \\ 1 Department of Psychology, Alma Mater Studiorum, University of Bologna, 40126 Bologna, Italy; \\ marco.deangelis6@unibo.it (M.d.A.); luca.pietrantoni@unibo.it (L.P.) \\ 2 IDOCAL (Research Institute on Personnel Psychology, \\ Organizational Development and Quality of Working Life), University of Valencia, 46010 Valencia, Spain; \\ nuria.tordera@uv.es \\ * Correspondence: guido.martinolli@studio.unibo.it or martinol@alumni.uv.es
}

check for updates

Citation: Martinolli, G.; de Angelis, M.; Tordera, N.; Pietrantoni, L. The Organizational Climate for Sustainable Commuting: An Italian Validation Study in the Academic Sector. Sustainability 2021, 13, 9215. https://doi.org/10.3390/su13169215

Academic Editor: Lucian-Ionel Cioca

Received: 15 June 2021

Accepted: 13 August 2021

Published: 17 August 2021

Publisher's Note: MDPI stays neutral with regard to jurisdictional claims in published maps and institutional affiliations.

Copyright: (c) 2021 by the authors. Licensee MDPI, Basel, Switzerland. This article is an open access article distributed under the terms and conditions of the Creative Commons Attribution (CC BY) license (https:// creativecommons.org/licenses/by/ $4.0 /)$.

\begin{abstract}
Promoting sustainable commuting represents a valuable contribution to tackle the climate crisis, and organizations could act as frontrunners in this regard. Accordingly, conceptualizing and measuring how organizational environments contribute to sustainable commuting has become relevant. This study aims to conceptualize and operationalize the construct of Organizational Climate for Sustainable Commuting (OCSC) and validate the OCSC scale in the Italian language. Data were gathered in an Italian university from 8542 participants. The validation was based on EFA and CFA, reliability, and aggregation indices analyses. To validate the scale, convergent, discriminant, internal construct, and criterion validities were assessed. Results confirmed a unidimensional structure of the tool, satisfactory reliability, justified aggregation, and provided evidence for validity. The proposed concept and scale offer a new perspective and measurement tool to be used when promoting sustainable commuting in the workplace is the objective.
\end{abstract}

Keywords: organizational climate; sustainable commuting; scale validation; travel behaviors

\section{Introduction}

Climate change is the "greatest challenge of the 21st century, threatening all aspects of the society in which we live, and the continuing delay in addressing the scale of the challenge increases the risks to human lives and health" [1] (p. 8). Climate change is estimated to cause roughly 250,000 more deaths between 2030 and 2050. It is expected to make extreme weather events more intense and frequent, and consequently, force the relocation of more than half of the world's population that lives within $60 \mathrm{~km}$ of the seaside because of the rising sea levels [2]. Due to the urgency of the topic, already in 2008, the American Psychological Association decided to set up a task force to identify solutions for tackling the primary sources of climate change from a psychological standpoint; both policies and research lines were suggested [3]. The leading cause is represented by the various human activities that produce greenhouse gasses [2], among which transportation and commuting travels, to or from work, and education places, play a relevant role [4,5]. In addition, transportation and commuting travel contribute to air pollution, as approximately $25 \%$ of air pollution in cities derives from traffic [1]. Empirical evidence about the impact of commuting on air quality is also provided by Bao and Zhang [6] and Lian and colleagues [7]. Indeed, in their studies focused on measuring the impact of COVID-19 lockdown imposed by the Chinese government on some of China's provinces, they found that the implemented travel restrictions consistently improved air quality in terms of SO2, PM2.5, PM10, NO2, and CO. The World Health Organization [2] strongly supports the design of interventions and the creation of tools supporting the reduction of greenhouse gases by promoting more sustainable travel behaviors and highly recommends the involvement of organizations and institutions in this process. This has been specially recommended when ascertaining 
that the actions that are taken so far for combating climate change (i.e., U.N. Sustainable Development Goal n. 13) have shown moderate effects [8].

Work and organizational psychologists have started to offer their knowledge and methodological rigor to organizations' sustainability initiatives and approaches to enhance employee pro-environmental behaviors (PEB). Indeed, beyond relying on individual-level theory or models [9], such as the Theory of Planned Behavior [10], the Norm Activation Model [11], or the Comprehensive Action Determination Model (CADM; [12]), also organizational level variables have been gradually started to be considered for explaining and changing these behaviors. More precisely, in 2012, Norton and colleagues [13] began to point out the relevance of conceptualizing specific organizational climates aimed at promoting pro-environmental behaviors and afterward proposed the first operationalization of it [14]. Also, Magill and colleagues [15] worked in such a direction by conceptualizing and operationalizing the organizational climate for climate sustainability $(\mathrm{C} 4 \mathrm{C})$ and highlighting the critical role that work environments, and not only individual characteristics, play in shaping pro-environmental behaviors. More concretely, it was found that changes in employee PEB may stem from having an adequate organizational context and not only by being strongly motivated and interested in environmental causes. Despite these essential theoretical and practical developments, some relevant aspects and literature gaps still need to be tackled and covered. First, research needs to define the appropriate focus of organizational climate referred to sustainability. Norton and colleagues [13] pointed out the usefulness of considering specific sustainability outcomes, as water/energy consumption or waste recycling, rather than the extremely comprehensive concept of sustainability. Otherwise, research on sustainability would be in danger of remaining meaningless. Indeed, tackling one of the many facets that compose this encompassing concept would allow direct assessments and targeted interventions. Second, in addition to the lack of measurements that Ones and Dilchert [16] already pointed out, the scientific literature is still missing validated scales measuring an organizational climate focused on sustainability. Finally, although Magill and colleagues [15] and Norton and colleagues [14] have already tested the usefulness of the organizational climate in pro-environmental behaviors, it is worth pointing out that such studies were conducted considering organizational climate at its individual level (i.e., psychological climate). Hence, an understanding of such variables at an organizational level is still missing.

As a consequence, it is relevant to provide researchers and practitioners with a helpful tool to investigate and shape sustainable commuting behaviors by considering how organizations foster environments that will facilitate such behaviors. Therefore, the purpose of the present research work is to provide the scientific community and practitioners with the novel construct of organizational climate for sustainable commuting (OCSC) and an instrument for its measurement with good psychometric properties. With this paper, we aim to test the validity and reliability of the OCSC scale in the Italian language. The OCSC is formulated as a multilevel construct that encompasses both individual- and group-level perceptions of the organizational environment. Thus, during the validation process, the justification of the aggregation of individual scores to unit scores is considered. Convergent and discriminant validities are conducted by checking the distinctiveness of individuallevel OCSC with sustainability-related constructs (i.e., perceived behavioral control and personal norms). Similarly, the criterion validity of the OCSC scale is tested with perceived behavioral control and personal norms, based on the theoretical rationale that workplace contexts influence the individual perceptions about what is adequate and expected and her/his decisional latitude to behave in this sense.

\subsection{A Definition and Operationalisation}

Norton and colleagues [13] first stated the relevance and need for considering organizational climates within models and theories explaining pro-environmental behaviors. Research in work and organizational psychology on other strategic organizational climates has demonstrated that these climates can have a strong influence on employee attitudes and 
behaviors as well as specific organizational outcomes (e.g., [17-19]). Accordingly, Kuenzi and Schminke [18] pointed out the relevant mediating role that facet-specific climates can play between organizational and personal inputs and organizational and individual facetspecific outcomes. Furthermore, as highlighted by Magill and colleagues [15], an additional reason supporting the usefulness of considering organizational climates in association with sustainability-related matters is that they are often perceived as too big and complex for human cognition [20]. Moreover, people do not necessarily behave rationally [21], and one's ability to respond with innovation to huge and paradoxical social issues, as is the case of climate change, is limited [22]. Hence, promoting organizational environments that encourage and remind sustainable ways of behaving could be particularly useful and practical [23]. Accordingly, and as mentioned previously, Norton and colleagues [14], Magill and colleagues [15], and Fatoki [24] have provided evidence of how climates referred to sustainability play a relevant role in shaping pro-environmental behaviors.

Sustainability is a comprehensive concept, defined as "the development that meets the needs of the present without compromising the ability of future generations to meet their own needs" [25] (p. 41). On the one hand, such comprehensiveness can be fruitful in conceptual and theoretical terms, but on the other hand, it may not ensure practical application. Assessing how much organizations are perceived as performing and acting sustainably in general terms may lead to spurious results unless a specific facet of sustainability is pointed out. Indeed, when a specific sustainable aspect is not considered (e.g., energy consumption, recycling, commuting), employees may gauge the general sense of sustainability by referring to different facets, thus failing to capture a consistent description of the organizational environment. It might indeed be the case that, for example, a specific organization promotes sustainability in terms of waste recycling, but it is not proactive in terms of energy consumption.

When it comes to sustainability, specifying a facet of reference may then be particularly useful in practical terms. In the present case, commuting has been taken as a reference since, as mentioned previously, it represents a relevant facet to consider when tackling climate change. Moreover, according to the Cambridge University Press's dictionary [26], commuting is defined as "the activity of traveling regularly between work and home"; thus, it can, by definition, be regarded as a behavior related to the workplace. Beyond this definitional standpoint, employers are increasingly interested in finding solutions for appropriately shaping commuting behaviors [27]. They claim that it would help organizations to meet their sustainability and capacity goal of reducing congestion [27]. Hence, despite not being included in the taxonomy by Ones and Dilchert [16] or the suggestions by Norton and colleagues [13], commuting behaviors should also be included in practical terms among their list of workplace aspects relevant to the promotion of sustainability and the tackling of climate change.

Focusing on the specific facet of sustainable commuting led to the conceptualization of its relevant organizational climate as a climate for something [28], hence considering it as a focused climate instead of a molar one [29]. More precisely, Schneider's [30] bandwidth argument, namely the necessity to link the concept of organizational climate to a specific aspect of an organization, has been embraced since it is beneficial in terms of predictive validity [28]. Accordingly, the OCSC can then be more precisely categorized as a focused strategic climate as opposed to a focused process climate, since it is more directly related to organizational outcomes, rather than to the internal processes that support the achievement of outcomes [29].

In light of all this, the OCSC is then conceptualized as the connection between personal and organizational inputs and outcomes when referring to the specific facet of sustainable commuting. Thus, based on the general definition of organizational climate provided by Schneider and Barbera [28], the organizational climate for sustainable commuting is here defined as: 
Definition 1. The shared perceptions and the meaning attached to the policies, practices, and procedures for sustainable commuting that people belonging to the same organization experience and are reflected on the extent to which sustainable commuting behaviors are being rewarded, facilitated, supported, and expected.

After defining OCSC, a review of the literature was conducted to identify validated scales or items for the operationalization of the construct. Scopus and Web-of-Science research platforms were consulted using different combinations of keywords, such as organizational climate, commuting, sustainability, green climate, environmental sustainability, and work climate. As for climate scales, no validated ones referring to either commuting or other specific facets of sustainability were found, except for the organizational climate of sustainability scale, by Arnaud and colleagues [31]. The scale measures the shared perceptions of sustainability in general with proper psychometric characteristics. Due to such paucity, also other adequately validated organizational climate scales, although not directly related to sustainability, were considered. As an example, the safety climate scale by Zohar and Luria [32] was regarded as an informative and solid starting point, because of its frequently confirmed and robust psychometric properties. As for climate items, although not directly referring to sustainable commuting, those referring to green organizational climate in hotel industries [33], to sustainability at universities [34], and to green work climate within organizations were considered [14].

Based on the literature overview, a pool of ten items was identified and shaped into the commuting framework. Such items were worded by implementing the referent-shift consensus composition model [35]. Indeed, LeBreton and Senter [36] pointed out that using such typology of composition models yields improved consensus since it refers to the level to which individual responses will be aggregated. Similarly, Wallace and colleagues [37] highlighted its usefulness, especially when examining performance-related outcomes with the relevant policies, practices, and procedures. In practical terms, items were worded as follows: "My organization provides information about sustainable modes of transport" (i.e., referent-shift) rather than "My organization provides me with information about sustainable modes of transport" (i.e., no referent-shift). As to the response scale, a fivepoint Likert scale ( $1=$ "Completely Disagree" and $5=$ "Completely Agree") was used for rating people's perceptions of the OCSC. This type of response scale was used for two main reasons: 1 . To give the possibility to the respondents to express a neutral perception; 2 . To consider the OCSC construct as a continuous variable during its validation. Subsequently, the items were analyzed by a panel of five experts with relevant experience and competence in the climate variable and, specifically, in designing and validating focused climate scales. This process yielded the final retainment of six items with ensured content validity (see Table 1). Indeed, the involvement of experts in such processes has been pointed out to be a best practice for ensuring this type of validity [38]. Finally, the validation of the scale was performed through the study that follows, which focuses on the validation of the scale in the Italian language.

Table 1. The Items of the Organizational Climate for Sustainable Commuting Scale.

\begin{tabular}{|c|c|c|}
\hline Item & Italian Worded Items & English Worded Items \\
\hline & $\begin{array}{l}\text { Con riferimento al mio viaggio da pendolare, } \\
\text { la mia università ... }\end{array}$ & $\begin{array}{l}\text { With reference to my commuting trip, } \\
\text { my university... }\end{array}$ \\
\hline OCSC1 & $\begin{array}{l}\ldots \text { monitora regolarmente l'utilizzo di } \\
\text { modalità di trasporto sostenibili }\end{array}$ & $\begin{array}{l}\text {.. regularly monitors the use of } \\
\text { sustainable modes of transport }\end{array}$ \\
\hline OCSC2 & $\begin{array}{l}\text {... incoraggia l'utilizzo di modalità di } \\
\text { trasporto sostenibili }\end{array}$ & $\begin{array}{c}\text {... spurs the use of sustainable modes of } \\
\text { transport }\end{array}$ \\
\hline OCSC3 & $\begin{array}{l}\text {... investe (es. sconti, agevolazioni, } \\
\text { offerte) nella promozione dell'utilizzo di } \\
\text { modalità di trasporto sostenibili }\end{array}$ & $\begin{array}{c}\text {... invests (e.g., discounts, reliefs, offers) } \\
\text { in the promotion of the use of sustainable } \\
\text { modes of transport }\end{array}$ \\
\hline
\end{tabular}


Table 1. Cont.

\begin{tabular}{|c|c|c|}
\hline Item & Italian Worded Items & English Worded Items \\
\hline OCSC 4 & $\begin{array}{l}\text {.. raccoglie le proposte di studenti e/o } \\
\text { del personale per aumentare l'utilizzo } \\
\text { delle modalità di trasporto sostenibili }\end{array}$ & $\begin{array}{l}\text {... collects the proposals of students } \\
\text { and/or staff members in order to increase } \\
\text { the use of sustainable modes of transport }\end{array}$ \\
\hline OCSC5 & $\begin{array}{l}\text {... fornisce adeguate informazioni } \\
\text { riguardo le modalità di trasporto } \\
\text { sostenibili }\end{array}$ & $\begin{array}{c}\text {... provides adequate information about } \\
\text { sustainable modes of transport }\end{array}$ \\
\hline OCsC6 & $\begin{array}{c}\text {... organizza regolarmente eventi volti } \\
\text { ad aumentare la consapevolezza circa } \\
\text { l'utilizzo di modalità di trasporto } \\
\text { sostenibili }\end{array}$ & $\begin{array}{l}\text {.. regularly organizes events aiming at } \\
\text { increasing the awareness of the use of } \\
\text { sustainable modes of transport }\end{array}$ \\
\hline
\end{tabular}

\subsection{OCSC, Personal Norms of Sustainability, and Perceived Behavioral Control}

It is not a novelty that the organizational context that a person experiences on a daily basis influences her/his personal norms [39,40], namely the "feelings of moral obligation" towards specific matters [11]. Indeed, spending a good amount of time in a context with specific rules and practices does necessarily shape the way a person feels about specific matters. In light of this and considering that focused organizational climates are, by definition, constructs that grasp an organizational context in relation to a specific matter, it can then be hypothesized that organizational climate(s) influence the norms a person has. Such a rationale has also found empirical support; Ifinedo [41] showed, through a study on a sample of 176 professionals working in the IT filed in Canada, that the organizational climate for security positively influenced the personal norms that employees had in this regard. For the provision of concurrent criterion validity, it is then hypothesized that:

Hypothesis 1. OCSC positively and directly relates to personal norms of sustainability, so that increased levels of OCSC relate to increased levels of personal norms.

Perceived behavioural control has been defined as "the amount of control a person subjectively experiences over her/his behaviour in a given situation and the ease of performing different behavioural alternatives" [42]. Considering the context of sustainable commuting, if this definition is put in relation with the above-reported one of OCSC, it is legitimate to hypothesize that such an organizational climate might positively relate to the perceived control that a person has in enacting sustainable commuting behaviours. Indeed, if, for example, it is considered an organizational context in which it is taken care of the practices and procedures related to sustainable commuting and in which such commuting behaviours are also rewarded or supported, it might then be imagined that the people that experience such a work environment might feel facilitated (i.e., perceived behavioural control) in enacting such behaviours. For the provision of the concurrent criterion validity, it is then also hypothesized that:

Hypothesis 2. OCSC positively and directly relates to perceived behavioural control, so that increased levels of OCSC relate to increased levels of perceived behavioural control.

\section{Method}

\subsection{Participants}

The sample was composed of 8542 participants. All of them were members of an Italian university. The average age was 26.9, with an SD of 11.86, ranging from a minimum of 17 to a maximum of 77 years. As for gender, $59.7 \%$ of the participants identified themselves as female, $37.2 \%$ as male, $2.4 \%$ of the participants did not identify themselves with any provided option, and $0.7 \%$ did not want to express themselves. As for the academic status, $76.8 \%$ of the participants were undergraduate, graduate, and doctoral students, $3.8 \%$ academic collaborators (e.g., linguistic experts, professionals with occasional contract), $7.7 \%$ teaching staff, and the remaining $11.7 \%$ were staff members. Participants belonged to 
44 different departments with an average size of 159.72 members, ranging from a minimum of 27 to a maximum of 367 people.

The sample was randomly split so as to use one half of it for conducting an exploratory factor analysis (EFA) and the second half for a confirmatory factor (CFA) and further internal consistency and validity analyses [43]. The first sub-sample was composed of 4236 university members, while the second sub-sample was composed of 4306 university members. Finally, aggregation analyses were conducted on the original whole sample so as to ensure a complete representation within each considered department.

\subsection{Procedure}

Data were collected following the approval obtained from the Ethical Committee of the aforementioned Italian institution. The online survey was sent out in January 2019 to the entire academic community. Additionally, also two email reminders were sent: two weeks from the launching date and one week before the closure of the survey. An online link was published on the mobility webpage of the Italian academic institution, where the participants could acquire information about the purposes of the research, data protection, and privacy issue management. The survey remained active for 31 days and was closed on the 9th of February, 2019.

\subsection{Measures}

Organizational climate for sustainable commuting was measured with the items reported in Table 1. The responses were collected through a 5-point Likert scale ranging from 1 (i.e., completely disagree) to 5 (i.e., completely agree). Cronbach's $\alpha$ was found to be 0.88 , suggesting an adequate internal consistency $[44,45]$.

Personal norms of sustainability, defined as feelings of moral obligation [11] towards sustainability-related matters, were measured employing a single-item scale [12]. The item was worded as follows, "When I have to select which means of transport to take, I always try to use a sustainable mode of transport". The responses were collected through a 5-point Likert scale ranging from 1 (i.e., completely disagree) to 5 (i.e., completely agree).

Perceived behavioral control is defined as a person's experience of having total control of a situation or being, at least partly, controlled by other people or situational conditions. It was measured using a three-item scale based on Klöckner and Blöbaum [12]. The items were worded as follows: 1 . "The circumstances oblige me to use the car for my continuous transfers"; 2. "It would be very difficult for me if I had to manage all my transfers by using only means of transport alternative to the car"; 3. "Reducing the use of the car depends completely on me". As for the response scale, a 5-point Likert scale ranging from 1 (i.e., completely disagree) to 5 (i.e., completely agree) was used. Cronbach's $\alpha$ was found to be 0.77 , suggesting an adequate internal consistency [44,45].

\subsection{Analyses}

First, the dataset was checked to identify missing data. Missing data amounted to $1.34 \%$, which is less than the limit of $5 \%$ for which data imputation is required [46].

Using IBM SPSS software, an EFA was conducted on one half of the sample considering the revised and updated suggestions by Lloret and colleagues [47]. After checking the normality assumption, Maximum Likelihood was used as the extraction method, since it provides the standard error and significance tests of the estimated parameters. No rotation method was specified since the items were expected to load on one single factor. The cut-off point for assigning an item to a factor was set to a minimum factor loading of 0.40 [48]. The number of factors to retain was decided by performing parallel analysis [47] by using FACTOR [49]. The parallel analysis was based on minimum rank factor analysis [50] and on an estimation of 1000 random data matrices values that correspond to the 95th percentile of the distribution of random data eigenvalues. The random values were then compared with derived eigenvalues to determine whether the parallel analyses supported the number of factors identified in the EFA. 
Once the factorial structure was determined through the EFA, it was tested in the second half of the sample by running a CFA. This analysis was conducted using the statistical software Mplus [51]. Maximum Likelihood estimation was implemented since data had a normal distribution. The model fit was assessed using several empirically supported indices so as to achieve a comprehensive evaluation of model fit: The comparative fit index (CFI), the Tucker-Lewis index (TLI), the root mean square error of approximation (RMSEA), and the standardized root mean square residual (SRMR). For the CFI and TLI, values above 0.90 are traditionally considered a reasonable model fit, whereas stringent recommendations suggest values close to 0.95 [52]. For the RMSEA and the SRMR, values below 0.08 are traditionally considered a reasonable model fit, whereas stringent recommendations suggest values close to 0.06 [52].

In order to evaluate the internal consistency, different reliability indices were estimated: Cronbach's alpha coefficient ( $\alpha$ ), Composite Reliability Value (rho), Coefficient H, and Omega Total. For the Cronbach's alpha coefficient, values above 0.70 are usually considered as sufficient [44]. For the Composite Reliability Value (Rho), values of 0.70 or greater indicate acceptable reliability [53]. Similarly, for Omega Total and Coefficient H, the commonly used cut-off point of 0.70 was considered [54]. However, no studies are present in the scientific literature that explicitly support such a cut-off point.

Since the scale was intended to also measure a unit-level construct (i.e., OCSC at a unit level), additional tests were conducted to assess aggregation. Aggregation allows to assess that each member's score was similar enough to those within their unit and that each member's score was significantly different to those among the other considered units. In doing so, the average deviation index (ADI) [55] and the $r_{W G(J)}$ [56] were computed and analyzed for the OCSC scale so as to ensure within-unit agreement. Since the Likert response scale to each OCSC item was composed of 5 points, the cut-off value for the ADI is 0.83 , more precisely the ADI must be smaller than 0.83 to indicate acceptable agreement [57]. On the other hand, $r_{W G(J)}$, values above 0.70 are considered to provide evidence of agreement [58]. As suggested by the scientific literature, we also computed the intraclass correlation coefficients [59]. ICC(1) was considered for evaluating the level of consistency of responses among unit members, while ICC(2) was considered for estimating the reliability of the unit means [60]. As suggested by Bliese and colleagues [61], itemlevel ICC(1)s were also computed and reported since they were pointed out as providing valuable and unique information about between-group variability. The commonly observed cut-off values for ICC(1) typically range between 0.05 and 0.20 [60], although LeBreton and Senter [36] have suggested that an ICC(1) of 0.05 represents a small-to-medium effect. Bliese [60] also suggests that values of ICC(2) above 0.70 should be considered acceptable. Finally, also a one-way analysis of variance (ANOVA) was carried out to determine whether there was statistically significant difference in between-units discrimination in sustainable commuting units. All aggregation analyses were conducted with the statistical software $\mathrm{R}$ (version 3.6.3) [62] by using the R package "multilevel" in its version 2.6 [63].

In order to assess the convergent validity of the OCSC scale, an average variance extracted (AVE) analysis was conducted, and the output was benchmarked against the cut-off point of 0.50 [64]. As for testing discriminant validity, a bivariate correlation analysis was first carried out since it is widely accepted that factor discrimination can be established when inter-factor correlations are below 0.85 [65]. Precisely, it was checked whether the correlations between OCSC and perceived behavioral control had a correlation index below 0.85 . Secondly, a CFA was run using individual scores $(n=4268)$ to show the distinctiveness of OCSC when compared with other types of sustainable-related psychological constructs (i.e., perceived behavioral control). A single factor model was compared to an alternative two-factor solution model in which the items of the two corresponding scales were loaded. Maximum Likelihood was considered as an estimation method since data were continuous and normally distributed. Regarding the practical fit indices based on modelling rationale, two criteria were used to compare the alternative models. First, if the difference between the NNFI values or between the TLI values of the competing models is less than 0.01 , it is 
considered practically inconsequential $[66,67]$. Second, support for a more parsimonious model can be claimed when the RMSEA increases by less than 0.015 [68]. Both CFAs were run using individual-level scores due to the sample size, since it affects the stability of the parameter estimates. Different studies $[69,70]$ have pointed out that using small sample sizes implies a considerable risk of misspecification of the model. Although the recommended "cut-off value" varies widely, scholars appear to agree that a sample size of at least 200 cases is recommended to evaluate the factorial structure of a test $[47,71,72]$. For this reason, carrying out the CFA at the departmental level $(n=44)$ was not possible in the present study. For testing the internal construct validity of the OCSC scale, Bayesian factors were considered. More precisely, as suggested by Kass [73], the BIC and AIC indices of different factorial models were compared. The indices describing the expected single-factor model of the OCSC scale were compared with the indices of some bi-factorial models of the OCSC scale obtained by randomly assigning the items to two different factors. Such analysis considered only models up to two dimensions within the OCSC scale, since considering more dimensions would have led to attribution of fewer than 3 items to each dimension, thus a number of items that is lower than what is suggested in the literature [47]. Finally, the criterion validity, more precisely concurrent validity, of the OCSC scale was tested with other sustainable-related constructs. Concretely, the incremental validity of the scale was tested by checking if OCSC added more explained variance to personal norms of sustainability after controlling for perceived behavioral control. With this purpose, two hierarchical regression analyses were run, both at an individual and departmental level.

\section{Results}

Data were subjected to factor analysis using Principal Axis Factoring without the selection of any rotation method. All KMO values for the individual items were greater than 0.85 , thus well above 0.50, and the Kaiser-Meyer-Olkin measure (KMO) was 0.88, indicating the data were sufficient for EFA. The Bartlett's test of sphericity $\chi^{2}(15)=11,345.63$, $p<0.001$ showed patterned relationships between the items. Using an eigenvalue cut-off of 1.0, there was one factor that explained a total variance of $61.36 \%$. Table 2 shows the unrotated factor loadings using a significant factor criterion of 0.40 . As for the parallel analysis, the KMO was 0.88 , the Bartlett's test of sphericity $\chi^{2}(15)=11,324.40, p<0.001$, and it advised the retention of one single factor. Accordingly, the Organizational Climate for Sustainable Commuting Scale was found to be mono-factorial.

Table 2. Factor Loadings (EFA).

\begin{tabular}{cc}
\hline Items & Factor Loadings $^{\mathbf{1}}$ \\
\hline OCSC 1 & 0.71 \\
OCSC 2 & 0.67 \\
OCSC 3 & 0.70 \\
OCSC 4 & 0.74 \\
OCSC 5 & 0.82 \\
OCSC 6 & 0.75 \\
\hline
\end{tabular}

${ }^{1} 1$ factor extracted, 4 iterations required.

The CFA tested a single-factor model. This model demonstrated good fit (i.e., $\mathrm{CFI}=0.99, \mathrm{TLI}=0.97, \mathrm{RMSEA}=0.07, \mathrm{SRMR}=0.019)$ after correlating the errors of items OCSC 3 with OCSC 2 and OCSC 4 with OCSC 3 , as suggested by modification indexes. As reported in Table 3, the standardized factor loadings ranged from 0.65 to 0.84 and were statistically significant (i.e., $p<0.001$ ). Based on these findings, the single-factor model of the OCSC Scale in its Italian version was accepted.

The descriptive statistics of the six OCSC items (i.e., mean, standard deviation, skewness, and kurtosis) can be found in Table 4 . With respect to internal consistency, Cronbach's alpha coefficient, Composite Reliability Value, and Omega Total of the OCSC scale amounted to 0.88 , while Coefficient $\mathrm{H}$ amounted to 0.89 . According to such coefficients, evidence of satisfactory reliability was provided. 
Table 3. Factor Loadings (CFA).

\begin{tabular}{ccc}
\hline Items & Factor Loadings & Sig. \\
\hline OCSC 1 1 & 0.71 & $p<0.001$ \\
OCSC 2 & 0.67 & $p<0.001$ \\
OCSC 3 & 0.70 & $p<0.001$ \\
OCSC 4 & 0.74 & $p<0.001$ \\
OCSC 5 & 0.82 & $p<0.001$ \\
OCSC 6 & 0.75 & $p<0.001$ \\
\hline
\end{tabular}

Table 4. Descriptive Statistics OCSC Items.

\begin{tabular}{ccccc}
\hline Items & Mean & S.D. & Skewness & Kurtosis \\
\hline OCSC 1 & 3.01 & 1.00 & -0.18 & -0.35 \\
OCSC 2 & 3.35 & 0.98 & -0.44 & 0.01 \\
OCSC 3 & 3.32 & 1.10 & -0.44 & -0.38 \\
OCSC 4 & 3.13 & 0.94 & -0.23 & 0.02 \\
OCSC 5 & 2.93 & 1.02 & -0.07 & -0.54 \\
OCSC 6 & 2.75 & 0.93 & 0.02 & -0.04 \\
\hline
\end{tabular}

The OCSC scale had a mean ADI score below the proposed cut-off of 0.83 , with low variability among the scores $(\mathrm{M}=0.77, \mathrm{SD}=0.07)$, proving the aggregation at a departmental level to be adequate. The $r_{W G(J)}$ value was 0.86 , thus consistently above the cut-off of 0.70 , suggesting there is strong agreement among the members within each department. The ANOVA value was $\mathrm{F}(43,6898)=2.90, p<0.001$, indicating significant differences among departments' scores. The ICC(1) for OCSC was 0.01 , indicating that the $1.0 \%$ of the variance of OCSC was explained by the clustering structure (i.e., department) of the data. Accordingly, also, the item-level ICC(1)s ranged from 0.01 to 0.02 (see Table 5). The ICC(2) value for OCSC was 0.66 , indicating low inter-rater reliability. However, ICC(1) values indicated a small effect, suggesting that additional investigations concerning the viability of aggregating scores within departments should be conducted. Finally, following LeBreton and Senter [36], inter-rater agreement indices (i.e., ADI and $r_{W G(J)}$ ) indicated strong agreement in the data. In summary, the above indices all together provided a reasonable justification for data aggregation.

Table 5. Item-Level ICC(1)s.

\begin{tabular}{ccccccc}
\hline Item & OCSC1 & OCSC2 & OCSC3 & OCSC4 & OCSC5 & OCSC6 \\
\hline ICC $(1)$ & 0.01 & 0.01 & 0.02 & 0.01 & 0.01 & 0.01 \\
\hline
\end{tabular}

The average proportion of item variance extracted (AVE) by the corresponding factor was 0.55 , thus higher than 0.50 , providing evidence for convergent validity. As for testing discriminant validity, the correlation between OCSC and perceived behavioral control amounted to $r=0.10(p<0.01)$, thus below the cut-off point of 0.85 , supporting factor discrimination. In addition, the comparison of the goodness of fit indices of the above described two different models provided evidence for discriminant validity. Indeed, as reported in Table 6, the one-factor model indicated poor fit, while the two-factor model provided evidence for a satisfactory fit if the abovementioned cut-offs points are considered. The differences between the two models were substantial (i.e., $\triangle$ RMSEA $=0.040$, $\Delta \mathrm{CFI}=0.090, \Delta \mathrm{TLI}=0.093$ ). With regard to internal construct validity, as reported in Table 7, the comparison of the Bayesian factors between the mono- and bi-factorial models provided evidence for the first one. Indeed, the BIC, AIC, and the Adjusted BIC indices were consistently higher for the single factor rather than for the bi-factorial solution, suggesting that considering the OCSC scale as being composed of one dimension is adequate. 
Table 6. Results of the Confirmatory Factor Analyses.

\begin{tabular}{cccccccc}
\hline Model & AIC & BIC & Adj. BIC & RMSEA & CFI & TLI & SRMR \\
\hline 1 Factor & $153,842.77$ & $154,014.46$ & $153,928.67$ & 0.20 & 0.72 & 0.63 & 0.11 \\
2 Factors & $149,880.39$ & $150,058.44$ & $149,969.46$ & 0.07 & 0.96 & 0.95 & 0.03 \\
\hline
\end{tabular}

Table 7. AIC and BIC Indices.

\begin{tabular}{cccc}
\hline Model & AIC & BIC & Adj. BIC \\
\hline 1 Factor & $59,472.07$ & $59,586.54$ & $59,529.34$ \\
2 Factors & $59,123.28$ & $59,244.10$ & $59,183.72$ \\
2 Factors & $59,431.29$ & $59,552.11$ & $59,491.73$ \\
2 Factors & $59,366.00$ & $59,486.82$ & $59,426.45$ \\
2 Factors & $59,457.64$ & $59,578.46$ & $59,518.08$ \\
\hline
\end{tabular}

Hierarchical regression analyses were conducted for assessing concurrent validity at the departmental level (see Table 8). The results indicated that the percentage of explained variance that OCSC added to personal norms of sustainability after controlling for perceived behavioral control was statistically significant $\left(\Delta R^{2}=0.003, p<0.001\right)$. The same occurred when the hierarchical regression analysis was carried out at the individual level (see Table 9). Results indicated that the percentage of explained variance added to personal norms of sustainability, after controlling for perceived behavioral control, was statistically significant $\left(\Delta R^{2}=0.02, p<0.001\right)$. In light of these results, it can then be stated that hypotheses $\mathrm{H} 1$ and $\mathrm{H} 2$ were empirically supported.

Table 8. Hierarchical Regression Analysis for Concurrent Validity (Departmental Level).

\begin{tabular}{|c|c|c|c|c|}
\hline \multirow{2}{*}{ Predictor } & \multicolumn{2}{|c|}{ Step 1} & \multicolumn{2}{|c|}{ Step 2} \\
\hline & $\beta$ & $\mathbf{R}^{2}$ & $\beta$ & $\Delta R^{2}$ \\
\hline PNS (DV) & & $0.08^{* * *}$ & & $0.003^{* * *}$ \\
\hline PBC & $0.28^{* * *}$ & & $0.27^{* * *}$ & \\
\hline OCSC & & & $0.50^{* * *}$ & \\
\hline
\end{tabular}

Note. PNS = Personal Norms of Sustainability; DV = Dependent Variable; PBC = Perceived Behavioral Control; OCSC = Organizational Climate for Sustainable Commuting; $* * * p<0.001$

Table 9. Hierarchical Regression Analysis for Concurrent Validity (Individual Level).

\begin{tabular}{|c|c|c|c|c|}
\hline \multirow{2}{*}{ Predictor } & \multicolumn{2}{|c|}{ Step 1} & \multicolumn{2}{|c|}{ Step 2} \\
\hline & $\beta$ & $\mathbf{R}^{2}$ & $\beta$ & $\Delta \mathrm{R}^{2}$ \\
\hline PNS (DV) & & $0.08^{* * *}$ & & 0.02 **** \\
\hline PBC & $0.28^{* * *}$ & & $0.27^{* * *}$ & \\
\hline OCSC & & & $0.13^{* * *}$ & \\
\hline
\end{tabular}

Note. PNS = Personal Norms of Sustainability; DV = Dependent Variable; PBC = Perceived Behavioral Control OCSC $=$ Organizational Climate for Sustainable Commuting; ${ }^{* * *} p<0.001$

\section{Discussion}

The present study was set out to conceptualize and validate the new construct of Organizational Climate for Sustainable Commuting (OCSC) and an instrument for its measurement with robust psychometric properties. Indeed, the relevant scientific literature is missing validation studies aimed at conceptualizing and making available new constructs for promoting more sustainable commuting behaviors. Thus, this paper contributes to the current literature by providing evidence of rigorous psychometric properties of the OCSC scale. In doing so, evidence of internal structure validity, reliability of the scores, convergent and discriminant validity with related variables was provided, as well as incremental validity through the association with perceived behavioral control. Finally, in line with the 
definition of climate as socially shared perceptions of the organizational environment [74] (p. 322), it also provided evidence of within- and between-department agreement of the OCSC scores, so as to confirm that the organizational climate for sustainable commuting is a social construct that operates within the actions and interactions of the departments/units of an organization.

\section{Conclusions}

It is an evidence-based fact that focused climates play a relevant role in shaping their corresponding behaviors [75-79]. Identifying the triggers of pro-environmental behaviors has become an increasingly important topic due to the climate crisis that the world population is and is going to face in the near future [2]. Hence, in addition to individual-level triggers, in the field of sustainability it has become a trend to explore also organizational-level variables as factors that shape pro-environmental behaviors [14,15]. Nevertheless, research about this type of higher-level factors remains scarce when the behavior of commuting is considered, despite the fact that transportation and commuting travels [4] represent a consistent contributor to the production of greenhouse gasses, thus climate change [2]. In light of this, the present study has been useful for defining and operationalizing a new organizational construct; a focused organizational climate. The scientific literature was consulted to identify previous studies that had as a main scope the promotion of sustainable commuting or sustainability-related behaviors based on organizational constructs. Only a few studies were found; thus, the conceptualization and operationalization of OCSC were also guided by the theoretical guidelines provided by Schneider and Barbera [28], Chan [35], and Glick [80], while the wording of the items was also modelled on the safety climate scale by Zohar and Luria [32], which is characterized by good and consistent psychometric properties. Practically, OCSC by definition values the importance of grasping the sharedness of perceptions, its items are worded accordingly to the referent-shift consensus composition model, and its statistical analyses are conducted at a clear and adequate level of analysis. In addition, it was shown that OCSC can reliably be aggregated to a department/unit level, providing evidence that such a construct should be further investigated when it comes to organizational psychology and behavioral change. Furthermore, it was made clear that organizational-level variables need to be included in the future theories or theoretical models that aim at explaining the antecedents of commuting behaviors and that are taken into account for shaping behaviours.

In terms of limitations, despite the valuable contribution of this study, it is important to note that the validation procedure took place at the departmental level. It was not possible to include other organizational entities in the study to validate the construct at the organizational level. However, the scale presents satisfactory indices at the departmental level. Future studies in which an organizational perspective is adopted to increase the validity of the scale are encouraged. Furthermore, it is worth pointing out that, if on one hand the shortness of the OCSC scale may represent relevant advantages in terms of time-efficiency especially for multidisciplinary studies, on the other hand it may represent a limitation when the aim is grasping a multifaceted concept of sustainability. It is then suggested to add to the herein validated scale items that aim to measure the desired additional facets.

The present validation of the Organizational Climate for Sustainable Commuting scale has notable practical implications. In line with Ruepert and colleagues [81], the present study provided additional evidence that organizational-level constructs should be considered for shaping travel behaviors, thus tackling climate change. As Page and Nelson [82] pointed out, organizations can act as drivers for the development of healthy behavior in the workplace (e.g., active commuting on e-bikes), which, in turn, can promote the well-being of the individual and the organization. In line with this principle, a specific scale emphasizing the role of organizations in promoting a sustainable mobility climate could increase awareness of the specific actions to be undertaken; for example, regularly monitoring the use of sustainable modes of transportation, investing (e.g., discounts, reliefs, 
offers), and collecting inputs to change behaviors. Furthermore, the conceptualization and operationalization of the herein proposed organizational construct and its relevant scale, represent a first step towards empowering HR managers with adequate tools for promoting more sustainable behaviors within the companies they work for. Indeed, it has been reported in the study by Willamowski and colleagues [23] that the "organization can and must not force employees to change but rather facilitate behavior change" (p. 3). Using OCSC as pivotal construct for such interventions may then represent a sound strategy for spurring and not forcing sustainable commuting behaviors.

Scientists and practitioners might adopt a new construct that can be particularly beneficial to consider when designing new interventions aimed at promoting sustainable commuting behaviors. Indeed, developing and implementing actions aimed at promoting OCSC might accelerate the process of promoting such behaviors. Organizational climate variables can be considered as constructs that grasp with a good approximation some specific aspects of the contexts people experience. Consequently, changing the context that people experience, rather than pointing at their individual idiosyncrasies, might be faster, hence particularly useful to the cause when the urgency of the climate crisis is considered.

Author Contributions: Conceptualization, G.M., M.d.A., N.T. and L.P.; validation, G.M. and M.d.A.; formal analysis, G.M.; investigation, G.M., M.d.A. and L.P.; data curation, G.M. and M.d.A.; writing-original draft preparation, G.M.; writing-review and editing, M.d.A., N.T. and L.P.; visualization, G.M.; supervision, N.T. and L.P.; project administration, M.d.A. and L.P. All authors have read and agreed to the published version of the manuscript.

Funding: This research received no external funding.

Institutional Review Board Statement: The study was conducted according to the guidelines of the Declaration of Helsinki, and approved by the Institutional Review Board (or Ethics Committee) of University of Bologna (protocol code 46936 and date of approval 28 April 2017).

Informed Consent Statement: Informed consent was obtained from all subjects involved in the study.

Data Availability Statement: The data presented in this study are available on request from the corresponding author.

Conflicts of Interest: The authors declare no conflict of interest.

\section{References}

1. WHO. COP24 Special Report: Health and Climate Change; WHO: Katowice, Poland, 2019.

2. WHO Climate Change and Health. Available online: https://www.who.int/news-room/fact-sheets/detail/climate-change-andhealth (accessed on 15 June 2021).

3. APA. Policy Recommendations; APA: Washington, DC, USA, 2009.

4. European Data Portal. The COVID-19 Related Traffic Reduction and Decreased Air Pollution in Europe; European Data Portal: Brussels, Belgium, 2020.

5. Molina, J.A.; Giménez-Nadal, J.I.; Velilla, J. Sustainable Commuting: Results from a Social Approach and International Evidence on Carpooling. Sustainability 2020, 12, 9587. [CrossRef]

6. Bao, R.; Zhang, A. Does lockdown reduce air pollution? Evidence from 44 cities in northern China. Sci. Total Environ. 2020, 731, 139052. [CrossRef]

7. Lian, X.; Huang, J.; Huang, R.; Liu, C.; Wang, L.; Zhang, T. Impact of city lockdown on the air quality of COVID-19-hit of Wuhan city. Sci. Total Environ. 2020, 742, 140556. [CrossRef]

8. Eurostat. Sustainable Development in the European Union: Monitoring Report on Progress towards the SDGS in an EU Context; Eurostat: Brussels, Belgium, 2019.

9. Chng, S.; Abraham, C.; White, M.P.; Hoffmann, C.; Skippon, S. Psychological theories of car use: An integrative review and conceptual framework. J. Environ. Psychol. 2018, 55, 23-33. [CrossRef]

10. Ajzen, I. The theory of planned behavior. Organ. Behav. Hum. Decis. Process. 1991, 50, 179-211. [CrossRef]

11. Schwartz, S.H. Normative Influences on Altruism. In Advances in Experimental Social Psychology; Academic Press: Cambridge, MA, USA, 1977; pp. 221-279.

12. Klöckner, C.A.; Blöbaum, A. A comprehensive action determination model: Toward a broader understanding of ecological behaviour using the example of travel mode choice. J. Environ. Psychol. 2010, 30, 574-586. [CrossRef]

13. Norton, T.A.; Zacher, H.; Ashkanasy, N.M. On the Importance of Pro-Environmental Organizational Climate for Employee Green Behavior. Ind. Organ. Psychol. 2012, 5, 497-500. [CrossRef] 
14. Norton, T.A.; Zacher, H.; Ashkanasy, N.M. Organisational sustainability policies and employee green behaviour: The mediating role of work climate perceptions. J. Environ. Psychol. 2014, 38, 49-54. [CrossRef]

15. Magill, M.S.; Yost, P.R.; Chighizola, B.; Stark, A. Organizational climate for climate sustainability. Consult. Psychol. J. Pract. Res. 2020, 72, 198-222. [CrossRef]

16. Ones, D.S.; Dilchert, S. Environmental Sustainability at Work: A Call to Action. Ind. Organ. Psychol. 2012, 5, 444-466. [CrossRef]

17. Alruqi, W.M.; Hallowell, M.R.; Techera, U. Safety climate dimensions and their relationship to construction safety performance: A meta-analytic review. Saf. Sci. 2018, 109, 165-173. [CrossRef]

18. Kuenzi, M.; Schminke, M. Assembling Fragments Into a Lens: A Review, Critique, and Proposed Research Agenda for the Organizational Work Climate Literature. J. Manag. 2009, 35, 634-717. [CrossRef]

19. Newman, A.; Round, H.; Wang, S.; Mount, M. Innovation climate: A systematic review of the literature and agenda for future research. J. Occup. Organ. Psychol. 2020, 93, 73-109. [CrossRef]

20. Gifford, R. The dragons of inaction: Psychological barriers that limit climate change mitigation and adaptation. Am. Psychol. 2011, 66, 290-302. [CrossRef]

21. Tversky, A.; Kahneman, D. Judgment under Uncertainty: Heuristics and Biases. Science 1974, 185, 1124-1131. [CrossRef] [PubMed]

22. Weick, K.E. Small wins: Redefining the scale of social problems. Am. Psychol. 1984, 39, 40-49. [CrossRef]

23. Willamowski, J.; Convertino, G.; Grasso, A. Leveraging organizations for sustainable commuting: A field study. CHI'14 2014, 72, 198-222.

24. Fatoki, O. Determinants of hotel employees' electricity saving intention: Extending the theory of planned behaviour. Entrep. Sustain. Issues 2020, 8, 86-97. [CrossRef]

25. World Commission on Environment and Development. Our Common Future: Report of the World Commission on the Environment and Development; World Commission on Environment and Development: Geneva, Switzerland, 1987.

26. Cambridge University Press. Cambridge Dictionary. Available online: https://dictionary.cambridge.org/dictionary/english/ commuting (accessed on 15 June 2021).

27. Kristal, A.; Whillans, A. Why It's so Hard to Change People's Commuting Behavior. Available online: https://hbr.org/2019/12/ why-its-so-hard-to-change-peoples-commuting-behavior (accessed on 15 June 2021).

28. Schneider, B.; Barbera, K.M. (Eds.) Introduction: The Oxford Handbook of Organizational Climate and Culture. In The Oxford Handbook of Organizational Climate and Culture; Oxford University Press: Oxford, UK, 2014; ISBN 9780199860715.

29. Ehrhart, M.G.; Raver, J.L. The effects of organizational climate and culture on productive and counterproductive behavior. In The Oxford Handbook of Organizational Climate and Culture; Schneider, B., Barbera, K.M., Eds.; Oxford University Press: Oxford, UK, 2014; pp. 153-176, ISBN 9780199860715.

30. Schneider, B. Organizational climates: An essay. Pers. Psychol. 1975, 28, 447-479. [CrossRef]

31. Arnaud, A.; Tinoco, J.K.; Rhoades, D.L. The organisational climate of sustainability: A survey. World Rev. Intermodal Transp. Res. 2013, 4, 99. [CrossRef]

32. Zohar, D.; Luria, G. A Multilevel Model of Safety Climate: Cross-Level Relationships Between Organization and Group-Level Climates. J. Appl. Psychol. 2005, 90, 616-628. [CrossRef]

33. Zientara, P.; Zamojska, A. Green organizational climates and employee pro-environmental behaviour in the hotel industry. $J$. Sustain. Tour. 2018, 26, 1142-1159. [CrossRef]

34. Dagiliūtè, R.; Liobikienè, G.; Minelgaite, A. Sustainability at universities: Students' perceptions from Green and Non-Green universities. J. Clean. Prod. 2018, 181, 473-482. [CrossRef]

35. Chan, D. Functional relations among constructs in the same content domain at different levels of analysis: A typology of composition models. J. Appl. Psychol. 1998, 83, 234-246. [CrossRef]

36. LeBreton, J.M.; Senter, J.L. Answers to 20 Questions About Interrater Reliability and Interrater Agreement. Organ. Res. Methods 2008, 11, 815-852. [CrossRef]

37. Wallace, J.C.; Edwards, B.D.; Paul, J.; Burke, M.; Christian, M.; Eissa, G. Change the Referent? A Meta-Analytic Investigation of Direct and Referent-Shift Consensus Models for Organizational Climate. J. Manag. 2016, 42, 838-861. [CrossRef]

38. Boateng, G.O.; Neilands, T.B.; Frongillo, E.A.; Melgar-Quiñonez, H.R.; Young, S.L. Best practices for developing and validating scales for health, social, and behavioral research: A primer. Front. Public Health 2018, 6, 149. [CrossRef]

39. Carrico, A.R.; Riemer, M. Motivating energy conservation in the workplace: An evaluation of the use of group-level feedback and peer education. J. Environ. Psychol. 2011, 31, 1-13. [CrossRef]

40. Boiral, O. The impact of operator involvement in pollution reduction: Case studies in Canadian chemical companies. Bus. Strateg. Environ. 2005, 14, 339-360. [CrossRef]

41. Ifinedo, P. Roles of organizational climate, social bonds, and perceptions of security threats on IS security policy compliance intentions. Inf. Resour. Manag. J. 2018, 31, 53-82. [CrossRef]

42. Klöckner, C.A.; Friedrichsmeier, T. A multi-level approach to travel mode choice-How person characteristics and situation specific aspects determine car use in a student sample. Transp. Res. Part F Traffic Psychol. Behav. 2011, 14, 261-277. [CrossRef]

43. Worthington, R.L.; Whittaker, T.A. Scale Development Research. Couns. Psychol. 2006, 34, 806-838. [CrossRef]

44. Cortina, J.M. What is coefficient alpha? An examination of theory and applications. J. Appl. Psychol. 1993, 78, 98-104. [CrossRef]

45. Nunnally, J.C. Psychometric Theory, 2nd ed.; McGraw-Hill: New York, NY, USA, 1978. 
46. Fichman, M.; Cummings, J.N. Multiple Imputation for Missing Data: Making the most of What you Know. Organ. Res. Methods 2003, 6, 282-308. [CrossRef]

47. Lloret-Segura, S.; Ferreres-Traver, A.; Hernández-Baeza, A.; Tomás-Marco, I. El análisis factorial exploratorio de los ítems: Una guía práctica, revisada y actualizada. An. Psicol. 2014, 30, 1151-1169. [CrossRef]

48. Williams, B.; Onsman, A.; Brown, T. Exploratory factor analysis: A five-step guide for novices. Australas. J. Paramed. 2010, 8. [CrossRef]

49. Lorenzo-Seva, U.; Ferrando, P.J. FACTOR: A computer program to fit the exploratory factor analysis model. Behav. Res. Methods 2006, 38, 88-91. [CrossRef]

50. Timmerman, M.E.; Lorenzo-Seva, U. Dimensionality assessment of ordered polytomous items with parallel analysis. Psychol. Methods 2011, 16, 209-220. [CrossRef]

51. Muthén, L.K.; Muthén, B.O. Mplus User's Guide, 8th ed.; Muthén \& Muthén: Los Angeles, CA, USA, 2017.

52. Hu, L.; Bentler, P.M. Cutoff criteria for fit indexes in covariance structure analysis: Conventional criteria versus new alternatives. Struct. Equ. Model. Multidiscip. J. 1999, 6, 1-55. [CrossRef]

53. Raykov, T. Estimation of congeneric scale reliability using covariance structure analysis with nonlinear constraints. Br. J. Math. Stat. Psychol. 2001, 54, 315-323. [CrossRef]

54. McNeish, D. Thanks coefficient alpha, we'll take it from here. Psychol. Methods 2018, 23, 412-433. [CrossRef] [PubMed]

55. Burke, M.J.; Finkelstein, L.M.; Dusig, M.S. On Average Deviation Indices for Estimating Interrater Agreement. Organ. Res. Methods 1999, 2, 49-68. [CrossRef]

56. James, L.R.; Demaree, R.G.; Wolf, G. Estimating within-group interrater reliability with and without response bias. J. Appl. Psychol. 1984, 69, 85-98. [CrossRef]

57. Burke, M.J.; Dunlap, W.P. Estimating Interrater Agreement with the Average Deviation Index: A User's Guide. Organ. Res. Methods 2002, 5, 159-172. [CrossRef]

58. Bliese, P.D. Multilevel Modeling in R (2.6). 2016. Available online: https://cran.r-project.org/doc/contrib/Bliese_Multilevel.pdf (accessed on 15 June 2021).

59. Bliese, P.D. Group Size, ICC Values, and Group-Level Correlations: A Simulation. Organ. Res. Methods 1998, 1, 355-373. [CrossRef]

60. Bliese, P.D. Within-group agreement, non-independence, and reliability: Implications for data aggregation and analysis. In Multilevel Theory, Research, and Methods in Organizations; Klein, K.K., Kozlowski, S.W.J., Eds.; Jossey-Bass: San Francisco, CA, USA, 2000; pp. 349-381.

61. Bliese, P.D.; Maltarich, M.A.; Hendricks, J.L.; Hofmann, D.A.; Adler, A.B. Improving the measurement of group-level constructs by optimizing between-group differentiation. J. Appl. Psychol. 2019, 104, 293-302. [CrossRef]

62. R Core Team. R: A Language and Environment for Statistical Computing. r Foundation for Statistical Computing. Available online: http:/ / www.r-project.org/ (accessed on 15 June 2021).

63. Bliese, P.D. Multilevel: Multilevel Functions; R Package Version 2.6. 2016. Available online: https://cran.microsoft.com/web/ packages/multilevel/multilevel.pdf (accessed on 15 June 2021).

64. Fornell, C.; Larcker, D.F. Evaluating Structural Equation Models with Unobservable Variables and Measurement Error. J. Mark. Res. 1981, 18, 39-50. [CrossRef]

65. Kline, R. Principles and Practice of Structural Equation Modeling, 4th ed.; The Guilford Press: New York, NY, USA, 2016.

66. Cheung, G.W.; Rensvold, R.B. Evaluating Goodness-of-Fit Indexes for Testing Measurement Invariance. Struct. Equ. Model. Multidiscip. J. 2002, 9, 233-255. [CrossRef]

67. Widaman, K.F. Hierarchically Nested Covariance Structure Models for Multitrait-Multimethod Data. Appl. Psychol. Meas. 1985, 9 , 1-26. [CrossRef]

68. Chen, F.F. Sensitivity of Goodness of Fit Indexes to Lack of Measurement Invariance. Struct. Equ. Model. Multidiscip. J. 2007, 14, 464-504. [CrossRef]

69. MacCallum, R.C.; Widaman, K.F.; Zhang, S.; Hong, S. Sample size in factor analysis. Psychol. Methods 1999, 4, 84-99. [CrossRef]

70. MacCallum, R.C.; Widaman, K.F.; Preacher, K.J.; Hong, S. Sample Size in Factor Analysis: The Role of Model Error. Multivar. Behav. Res. 2001, 36, 611-637. [CrossRef]

71. Ferrando, P.J. Anguiano-Carrasco El análisis factorial como técnica de investigación en psicología. Pap. Psicólogo 2010, 31, 18-33.

72. Lloret, S.; Ferreres, A.; Hernández, A.; Tomás, I. El análisis factorial exploratorio de los ítems: Análisis guiado según los datos empíricos y el software. An. Psicol. 2017, 33, 417. [CrossRef]

73. Kass, R.E.; Raftery, A.E. Bayes Factors. J. Am. Stat. Assoc. 1995, 90, 773-795. [CrossRef]

74. Zohar, D. Safety climate: Measurement, conceptualization, and improvement. In The Oxford Handbook of Organizational Climate and Culture; Schneider, B., Barbera, K.M., Eds.; Oxford University Press: Oxford, UK, 2014; pp. 317-334, ISBN 9780199860715.

75. Beus, J.M.; Payne, S.C.; Bergman, M.E.; Arthur, W. Safety climate and injuries: An examination of theoretical and empirical relationships. J. Appl. Psychol. 2010, 95, 713-727. [CrossRef]

76. Christian, M.S.; Bradley, J.C.; Wallace, J.C.; Burke, M.J. Workplace safety: A meta-analysis of the roles of person and situation factors. J. Appl. Psychol. 2009, 94, 1103-1127. [CrossRef]

77. Curcuruto, M.; Griffin, M.A.; Kandola, R.; Morgan, J.I. Multilevel safety climate in the UK rail industry: A cross validation of the Zohar and Luria MSC scale. Saf. Sci. 2018, 110, 183-194. [CrossRef] 
78. Park, S.; Jo, S.J. The impact of proactivity, leader-member exchange, and climate for innovation on innovative behavior in the Korean government sector. Leadersh. Organ. Dev. J. 2018, 39, 130-149. [CrossRef]

79. Whitman, D.S.; Caleo, S.; Carpenter, N.C.; Horner, M.T.; Bernerth, J.B. Fairness at the collective level: A meta-analytic examination of the consequences and boundary conditions of organizational justice climate. J. Appl. Psychol. 2012, 97, 776-791. [CrossRef]

80. Glick, W.H. Conceptualizing and Measuring Organizational and Psychological Climate: Pitfalls in Multilevel Research. Acad. Manag. Rev. 1985, 10, 601-616. [CrossRef]

81. Ruepert, A.M.; Keizer, K.; Steg, L. The relationship between Corporate Environmental Responsibility, employees' biospheric values and pro-environmental behaviour at work. J. Environ. Psychol. 2017, 54, 65-78. [CrossRef]

82. Page, N.C.; Nilsson, V.O. Active Commuting: Workplace Health Promotion for Improved Employee Well-Being and Organizational Behavior. Front. Psychol. 2017, 7, 1994. [CrossRef] [PubMed] 